\title{
Projection-Specific Potentiation of Ventral Pallidal Glutamatergic Outputs after Abstinence from Cocaine
}

\author{
Liran A. Levi, Kineret Inbar, Noa Nachshon, Nimrod Bernat, Ava Gatterer, Dorrit Inbar, and ๑Yonatan M. Kupchik \\ Department of Medical Neurobiology, Institute for Medical Research Israel-Canada, Faculty of Medicine, The Hebrew University of Jerusalem, Jerusalem \\ 9112102, Israel
}

\begin{abstract}
The ventral pallidum (VP) is a central node in the reward system that is strongly implicated in reward and addiction. Although the majority of VP neurons are GABAergic and encode reward, recent studies revealed a novel glutamatergic neuronal population in the VP [VP neurons expressing the vesicular glutamate transporter $\left.2\left(\mathrm{VP}_{\mathrm{VGluT2}}\right)\right]$, whose activation generates aversion. Withdrawal from drugs has been shown to induce drastic synaptic changes in neuronal populations associated with reward, such as the ventral tegmental area (VTA) or nucleus accumbens neurons, but less is known about cocaine-induced synaptic changes in neurons classically linked with aversion. Here, we demonstrate that $\mathrm{VP}_{\mathrm{VGluT2}}$ neurons contact different targets with different intensities, and that cocaine conditioned place preference (CPP) training followed by abstinence selectively potentiates their synapses on targets that encode aversion. Using whole-cell patch-clamp recordings combined with optogenetics in male and female transgenic mice, we show that $\mathrm{VP}_{\mathrm{VGluT2}}$ neurons preferentially contact aversion-related neurons, such as lateral habenula neurons and VTA GABAergic neurons, with minor input to reward-related neurons, such as VTA dopamine and VP GABA neurons. Moreover, after cocaine CPP and abstinence, the $\mathrm{VP}_{\mathrm{VGluT} 2}$ input to the aversionrelated structures is potentiated, whereas the input to the reward-related structures is depressed. Thus, cocaine CPP followed by abstinence may allow $\mathrm{VP}_{\mathrm{VGluT2}}$ neurons to recruit aversion-related targets more readily and therefore be part of the mechanism underlying the aversive symptoms seen after withdrawal.
\end{abstract}

Key words: Ventral pallidum; VGluT2 neurons; Lateral habenula; cocaine; slice electrophysiology; optogenetics

Significance Statement

The biggest problem in drug addiction is the high propensity to relapse. One central driver for relapse events is the negative aversive symptoms experienced by addicts during withdrawal. In this work, we propose a possible mechanism for the intensification of aversive feelings after withdrawal that involves the glutamatergic neurons of the ventral pallidum. We show not only that these neurons are most strongly connected to aversive targets, such as the lateral habenula, but also that, after abstinence, their synapses on aversive targets are strengthened, whereas the synapses on other rewarding targets are weakened. These data illustrate how after abstinence from cocaine, aversive pathways change in a manner that may contribute to relapse.

\section{Introduction}

The ventral pallidum (VP) is a central structure of the reward system that consists mainly of GABAergic neurons (Gritti et al., 1993; Root et al., 2015). In addition to GABAergic neurons, some VP neurons express the vesicular glutamate transporter 2 (VGluT2; Geisler and Zahm, 2005; Hur and Zaborszky, 2005; Geisler et al., 2007), indicating these neurons release glutamate (Faget et al., 2018; Tooley et al., 2018). Recent anatomical studies

Received April 23, 2019; revised Dec. 5, 2019; accepted Dec. 10, 2019.

Author contributions: L.A.L., D.I., and Y.M.K. designed research; L.A.L., K.I., N.N., N.B., and A.G. performed research; L.A.L., K.I., D.I., and Y.M.K. analyzed data; L.A.L., D.I., and Y.M.K. wrote the paper.

This study was supported by the Israeli Science Foundation (Grant 1381/15 to Y.M.K.) and by the Faye \& Max Warshafsky Medical Research Scholarship awarded to L.A.L.

The authors declare no competing financial interests.

Correspondence should be addressed to Yonatan M. Kupchik at yonatank@ekmd.huji.ac.il.

https://doi.org/10.1523/JNEUROSCI.0929-19.2019

Copyright $\odot 2020$ the authors have identified the inputs and targets of these $\mathrm{VP}_{\mathrm{VGluT2}}$ neurons. As $\mathrm{VP}_{\mathrm{GABA}}$ neurons, they receive major inputs from the nucleus accumbens (NAc), amygdala, midbrain, and more (Tooley et al., 2018). Their projections cover a wide array of brain regions, with particular emphasis on the lateral habenula ( $\mathrm{LHb}$ ) and the ventral tegmental area (VTA; Faget et al., 2018). Thus, VP ${ }_{\text {VGluT2 }}$ neurons seem to be involved in networks similar to those of $\mathrm{VP}_{\mathrm{GABA}}$ neurons.

Despite their similar connectivity, $\mathrm{VP}_{\mathrm{VGluT} 2}$ and $\mathrm{VP}_{\mathrm{GABA}}$ neurons were recently suggested to have opposing behavioral roles in the context of reward seeking (Heinsbroek et al., 2017a; StephensonJones et al., 2017; Faget et al., 2018; Tooley et al., 2018). Thus, activation of $\mathrm{VP}_{\mathrm{VGluT}}$ neurons in a real-time conditioned place preference $(\mathrm{CPP})$ task induces place aversion, whereas $\mathrm{VP}_{\mathrm{GABA}}$ activation induces reward seeking (Faget et al., 2018). Likewise, in vivo recordings from both populations revealed that $\mathrm{VP}_{\mathrm{VGluT2}}$ neurons increase their firing rate during aversive experiences, 
whereas $\mathrm{VP}_{\mathrm{GABA}}$ neurons fire when seeking or receiving reward (Richard et al., 2016; Stephenson-Jones et al., 2017). Therefore, although the GABAergic VP as a whole encodes hedonic values of reward (Smith and Berridge, 2005; Tindell et al., 2006; Tachibana and Hikosaka, 2012; Richard et al., 2016, 2018; Ahrens et al., 2018) and the $\mathrm{VP}_{\text {VGluT2 }}$ neurons participate in similar networks as $\mathrm{VP}_{\mathrm{GABA}}$ neurons, $\mathrm{VP}_{\mathrm{VGluT2}}$ neurons are considered to encode aversive feelings.

Withdrawal from drugs of abuse presents the most difficult challenge drug addicts face when trying to quit drugs. This difficulty is partly attributed to the aversive withdrawal symptoms that develop during withdrawal. In addition, the genetic and synaptic changes that underlie addictive behavior are considered to achieve their full, steady-state manifestation only after withdrawal from drug use (Kalivas and Volkow, 2005). Many synaptic changes have been described in the reward system after withdrawal, including in the VP (Kupchik et al., 2014; Creed et al., 2016; Heinsbroek et al., 2017b). However, it is not known whether $\mathrm{VP}_{\mathrm{VGluT2}}$ neurons, given their potential role in aversive withdrawal, undergo plasticity after addicts quit drugs. Here, we use patch-clamp electrophysiology with optogenetics and transgenic mice to examine how well $\mathrm{VP}_{\mathrm{VGluT2}}$ neurons connect with neurons in the main targets of the VP [VTA, LHb, mediodorsal thalamus (MDT) ] and in the VP itself (with other $\mathrm{VP}_{\mathrm{VGluT2}}$ neurons or with $\mathrm{VP}_{\mathrm{GABA}}$ neurons), and whether the different connections of $\mathrm{VP}_{\mathrm{VGluT2}}$ neurons undergo synaptic plasticity with cocaine $\mathrm{CPP}$ followed by prolonged abstinence.

\section{Materials and Methods}

Animals. Male and female VGluT2-IRES-Cre transgenic mice (strain $\# 007905$, The Jackson Laboratory), which express Cre recombinase in cells expressing VGluT2 under internal ribosome entry site (IRES), were crossed in-house with Ai9 Cre-dependent fluorescent reporter mice (strain \#007909, The Jackson Laboratory). The crossed VGluT2-IRESCre $\times$ Ai9 mice expressed the red fluorescent protein tdTomato in all VGluT2 glutamatergic neurons. Mice were group housed under a $12 \mathrm{~h}$ reverse light cycle (lights off at 8:00 A.M.). All mice had a C57BL/6J background and were bred in-house.

Viral injections. Ten-week-old mice were anesthetized with isoflurane (SomnoSuite, Kent Scientific) and fixed in a stereotaxic frame (model 940, Kopf). Bilateral holes were drilled in the skull, and the viral constructs [AAV2-EF1a-DIO-hChR2(H134R)-eYFP (enhanced yellow fluorescent protein), University of North Carolina Vector Core or AAV9-EF1-DIO-ArchT-YFP, Edmond and Lily Safra Center for Brain Sciences Vector Core Facility] were microinjected through a 30 ga NanoFil syringe (World Precision Instruments; $300 \mathrm{nl}$ per hemisphere, 100 $\mathrm{nl} / \mathrm{min}$, needle retracted $5 \mathrm{~min}$ after injection terminated) into the subcommissural ventral pallidum (injection coordinates were in millimeters relative to bregma: anteroposterior, +0.4 ; mediolateral, 1.1 ; dorsoventral, -5$)$ of VGluT2-IRES-Cre $\times$ Ai9 mice.

Behavioral procedure. Behavioral procedures started after 2 weeks of acclimation to the reverse light cycle, when the mice were $\sim 12$ weeks old. All mice were trained in the unbiased cocaine CPP paradigm- a $30 \times 30$ $\mathrm{cm}$ arena was divided in two, each side with different wall patterns and floor texture (see Fig. 5A). On the first day, all mice were allowed to explore the arena freely. Then, experimental mice received one daily injection of either cocaine (in the paired side, $15 \mathrm{mg} / \mathrm{kg}$, i.p.) or saline (in the unpaired side). Control mice received saline injections on both sides. Each side of the box served as a cocaine-paired side for half of the mice. Cocaine/saline injections alternated daily until each mouse received four injections of each. Then, mice were left in their cages for $14 \mathrm{~d}$ before electrophysiological recordings began or the CPP test was performed. In the CPP test, mice were positioned in the center of the box and allowed to move freely for $15 \mathrm{~min}$. Movement was recorded using a camera and MediaRecorder software (Noldus) and later analyzed with EthoVision X (Noldus). CPP score was calculated as the ratio between the difference in time spent between the cocaine-paired and unpaired sides and the total time $[\mathrm{CPP}$ score $=($ time in paired zone - time in unpaired zone $) /($ time in paired zone + time in unpaired zone)]. All procedures were approved by the Research Animal Care Committee of the Hebrew University.

Slice preparation. Slices were prepared as previously described (Kupchik et al., 2015). Mice were anesthetized (150 mg/kg ketamine $\mathrm{HCl})$, decapitated, and sagittal or coronal slices $(200 \mathrm{~m})$ of the VP were prepared (VT1200S vibratome, Leica). Slices were transferred to a vial containing aCSF (in mM: $126 \mathrm{NaCl}, 1.4 \mathrm{NaH}_{2} \mathrm{PO}_{4}, 25 \mathrm{NaHCO}_{3}, 11$ glucose, $1.2 \mathrm{MgCl}_{2}, 2.4 \mathrm{CaCl}_{2}, 2.5 \mathrm{KCl}, 2.0 \mathrm{Na}$-pyruvate, 0.4 ascorbic acid, bubbled with $95 \% \mathrm{O}_{2}$ and $5 \% \mathrm{CO}_{2}$ ) and a mixture of $5 \mathrm{~mm}$ kynurenic acid and $100 \mathrm{M} \mathrm{D}-\mathrm{AP}$. Slices were stored at room temperature $\left(22-24^{\circ} \mathrm{C}\right)$ until recording.

In vitro whole-cell recording. All recordings were collected at $32^{\circ} \mathrm{C}$ (TC-344B, Warner Instruments). The VP, MDT, VTA, and LHb were identified using a mouse atlas (Paxinos and Franklin, 2001). Neurons were visualized with a BX51WI microscope (Olympus). Inhibitory synaptic transmission was blocked with picrotoxin $(0.1 \mathrm{~mm})$. MultiClamp 700B (Molecular Devices) was used to record EPSCs in whole-cell configuration. Glass microelectrodes (1.3-2 M $\Omega$ ) were filled with internal solution (in mM: 128 cesium methanesulfonate, 10 HEPES potassium, 1 EGTA, $1 \mathrm{MgCl}_{2}, 10 \mathrm{NaCl}, 2.0 \mathrm{Mg}$-ATP, $0.3 \mathrm{Na}-\mathrm{GTP}$, and $1 \mathrm{QX}-314$, at $\mathrm{pH} 7.2-7.3$ and $\sim 280 \mathrm{mOsm})$. In the ventral pallidum, we identified glutamatergic neurons by the fluorescence of tdTomato. Nonfluorescent neurons in the VP were considered to be the classical GABAergic pallidal cells based on their physiological (more depolarized) and morphological (smaller soma) difference from cholinergic neurons (Bengtson and Osborne, 2000; Kupchik and Kalivas, 2013) and the fact that they comprise $\sim 90 \%$ of the nonglutamatergic neurons in the VP (Gritti et al., 1993; Root et al., 2015). Recordings started no earlier than $10 \mathrm{~min}$ after the cell membrane was ruptured. Data were acquired at $10 \mathrm{kHz}$ and filtered at 2 $\mathrm{kHz}$ using AxoGraph X software (AxoGraph Scientific). To evoke neurotransmitter release from $\mathrm{VP}_{\text {VGluT2 }}$ neurons, we used a $470 \mathrm{~nm}$ LED light source (Mightex Systems; 0.1-1 ms in duration) directed to the slice through the objective. The stimulation pulse $(1 \mathrm{~ms})$ intensity chosen evoked a $50 \%$ of maximal EPSC at $-70 \mathrm{mV}$. Recordings were collected every $20 \mathrm{~s}$. To inactivate $\mathrm{VP}_{\mathrm{VGluT} 2}$ terminals (via ArchT activation), we used a $560 \mathrm{~nm}$ LED light source (Mightex Systems) through the objective. Series resistance (Rs), membrane input resistance, and membrane capacitance, measured using a $-2 \mathrm{mV}$ depolarizing step (10 ms) given with each stimulus, were always monitored online. Recordings with unstable Rs values, or when Rs values exceeded $20 \mathrm{M} \Omega$, were aborted.

Measuring the AMPA/NMDA ratio. AMPA currents were first measured at $-70 \mathrm{mV}$ to ensure stability of response. The membrane potential was then gradually increased to $+40 \mathrm{mV}$. Recording of currents resumed 5 min after reaching $+40 \mathrm{mV}$ to allow stabilization of cell parameters. First, we obtained the total current composed of both AMPA and NMDA components. Then, the NMDA receptor blocker D-AP5 (catalog \#ab120003, Abcam) was bath-applied ( $50 \mu \mathrm{M})$ to block NMDA currents, and recording of AMPA currents at $+40 \mathrm{mV}$ was started after $2 \mathrm{~min}$. NMDA currents were obtained by subtracting the AMPA currents from the total current at $+40 \mathrm{mV}$.

Experimental design and data analysis. Experiments in Figures 1, 2, and 3, $A-C$ and $F-J$ (see also Fig. 5) were conducted in a between-subjects design and were evaluated using unpaired Student's $t$ test or one-way ANOVA. Experiments in Figures 3, $D-E$, and 4 were conducted in a within-subject design and were analyzed using the paired Student's $t$ test. Statistics were performed using GraphPad Prism 8.0 (GraphPad Software Inc.).

\section{Results}

\section{The functional connectivity of $\mathrm{VP}_{\mathrm{VGluT2}}$ neurons}

VP neurons send projections to various brain regions, some linked to reward (e.g., dopaminergic VTA neurons) and some to aversion (e.g., $\mathrm{LHb}$ ). The subpopulation of $\mathrm{VP}_{\mathrm{VGluT2}}$ neurons was recently shown to induce aversion (Faget et al., 2018; Tooley et al., 2018), but it is not known whether these neurons indeed participate in all major VP connections. To examine this, we first 
tested whether $\mathrm{VP}_{\mathrm{VGluT2}}$ neurons contact six of the major targets of the $\mathrm{VP}$-local $\mathrm{VP}_{\text {VGluT2 }}$ and $\mathrm{VP}_{\mathrm{GABA}}$ neurons $\left(\mathrm{VP}_{\mathrm{GABA}}\right.$ neurons were non-VGluT2 neurons that showed basic physiological parameters typical to $\mathrm{VP}_{\mathrm{GABA}}$ but not cholinergic neurons; see Materials and Methods), VTA GABA-like $\left(\mathrm{VTA}_{\mathrm{GABA}}\right.$, identified by lack of $I_{\mathrm{h}}$ current) and dopamine-like (VTA $_{\mathrm{DA}}$, identified by presence of $I_{\mathrm{h}}$ current) neurons, MDT neurons, and $\mathrm{LHb}$ neurons (Fig. $1 A-C$ ). We injected VGluT2-Cre mice with AAV-DIO-ChR2eYFP in the VP and recorded from each of the targets to examine the proportion of cells receiving input. A cell was considered to receive input from $\mathrm{VP}_{\mathrm{VGluT} 2}$ neurons if stimulation of the terminals generated EPSCs of at least $30 \mathrm{pA}$ in at least $50 \%$ of the trials $\left(50 \mathrm{pA}\right.$ in the $\mathrm{VP}_{\mathrm{VGluT2}}$ neurons due to ChR2-mediated currents; see below). Within the $\mathrm{VP}$, we found that $\mathrm{VP}_{\mathrm{V}^{-}}$ GluT2 neurons maintain a strong local network with both $\mathrm{VP}_{\mathrm{VGluT} 2}$ and $\mathrm{VP}_{\mathrm{GABA}}$ neurons, as $94 \%$ ( 17 of 18 ) and $82 \%$ ( 18 of 22) of these neurons, respectively, showed $\mathrm{VP}_{\text {VGluT2 }}$ input (Fig. 1D). Note that in $\mathrm{VP}_{\mathrm{VGluT2}}$ neurons, part of the current is expected to be mediated by the ChR2 itself, but in separate experiments, we found that the amplitude of ChR2mediated currents at $-70 \mathrm{mV}$ was $<10$ pA (Fig. 1D, inset), negligible compared with the synaptic current measured. When examining outside of the VP, the $\mathrm{LHb}$ showed the highest proportion of cells with $\mathrm{VP}_{\text {VGluT2 }}$ input (64\%), whereas only $30 \%$ of VTA neurons, independent of their subtype, showed $\mathrm{VP}_{\mathrm{VGluT}}$ input (Fig. 1D). In the MDT, half of the cells showed $\mathrm{VP}_{\mathrm{VGluT}}$ input. Recordings were performed in the presence of the $\mathrm{GABA}_{\mathrm{A}}$ receptor blocker picrotoxin to prevent possible GABA currents (Tooley et al., 2018).
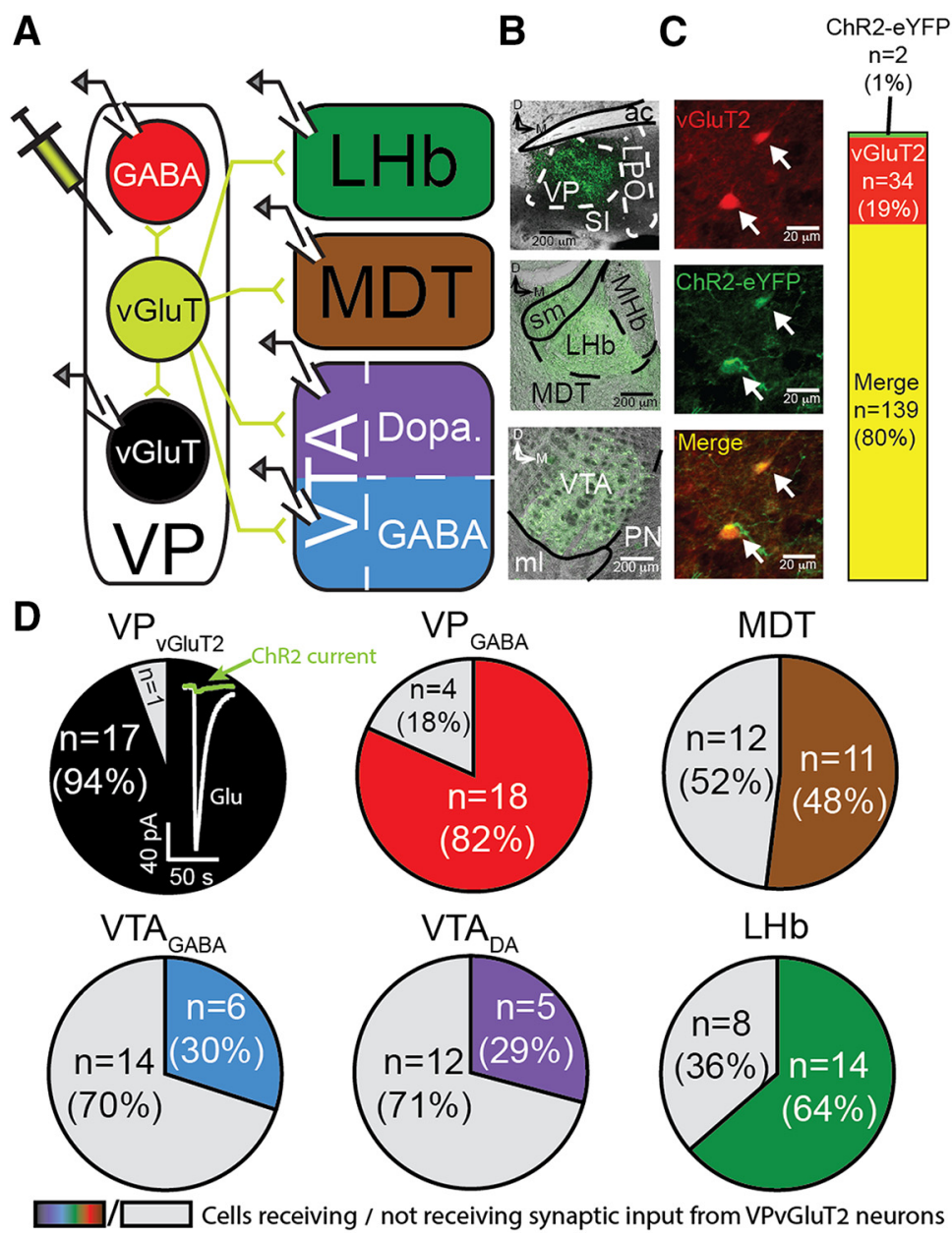

Figure 1. Projection patterns of $V P_{\mathrm{VGluT} 2}$ neurons. $A$, Schematic representation of the recording setup. An AAV expressing ChR2 in a Cre-dependent manner (AAV2-DI0-ChR2-eYFP) was injected into the VP of crossed VGluT2-IRES-Cre $\times$ Ai9 mice. Thus, $\mathrm{VP}_{\mathrm{VGluT2}}$ neurons exclusively expressed ChR2 and tdTomato. Recordings were performed in each of the depicted targets while transmitter release was evoked optogenetically. $\boldsymbol{B}$, Photomicrographs of injection site in the VP (top), VP $\mathrm{VGluT}_{2}$ axons in the $\mathrm{MDT} / \mathrm{LHb}$ (middle), and VTA (bottom). Note the stronger fluorescence in LHb compared with adjacent MDT. ac, Anterior commissure; LPO, lateral preoptic area; MHb, medial habenula; $\mathrm{ml}$, medial lemniscus; PN, paranigral nucleus; SI, substantia innominate; sm, stria medularis of the thalamus. C, Photomicrographs showing tdTomato expression in VP $\mathrm{VGluT2}_{2}$ neurons (top), ChR2-eYFP expression (middle), and the merge (bottom). Only two cells of 141 that expressed ChR2-eYFP did not coexpress tdTomato, indicating ChR2 expression was restricted to $\mathrm{VP}_{\mathrm{VGluT2}}$ neurons (right). D, Proportion of recorded neurons that showed VP $\mathrm{VGluT2}_{\mathrm{V}}$ input (of all recorded neurons in that region) in each region/cell type. Gray, no response; color, showed response. VP $\mathrm{VGluT2}_{2}$ neurons inset, Representative evoked postsynaptic glutamatergic currents (Glu; white) and presumed ChR2-mediated currents [in the presence of $10 \mu \mathrm{M}$ CNQX and $50 \mu \mathrm{m}$ picrotoxin (green)] recorded from VP $\mathrm{VGluT2}_{2}$ neurons. ChR2-mediated currents were negligible in amplitude.

\section{VP $P_{\text {VGluT2 }}$ neurons may make the}

\section{strongest synapses on each other and on LHb neurons}

We next examined whether the synaptic features of $\mathrm{VP}_{\mathrm{VGluT} 2}$ terminals are similar between the different targets. To evaluate the postsynaptic characteristics of each synapse, we measured the ratio between AMPA and NMDA current amplitudes. This ratio is used widely as a surrogate to estimate changes or differences in synaptic efficacy, with the rule of thumb being that higher ratios indicate stronger synapses (Kauer and Malenka, 2007; Kourrich et al., 2007; Counotte et al., 2014; Neumann et al., 2016; Pascoli et al., 2018; although this interpretation is controversial, as is discussed below). Our data show that different $\mathrm{VP}_{\mathrm{VGluT2}}$ projections show different AMPA/NMDA $(A / N)$ ratios [Fig. $2 A$; Table 1; one-way ANOVA, main group (projection) effect, $F_{(5,25)}=9.63$, $p<0.0001]$. The highest ratios were seen in $\mathrm{VP}_{\mathrm{VGluT} 2}$ terminals on each other $(A / N$ ratio $=1.94 \pm 0.8$ i.e., mean $\pm S D$; Tukey's multiple-comparisons tests; $\mathrm{VP}_{\mathrm{VGluT2}}$ compared with
$\mathrm{VP}_{\mathrm{GABA}}: q_{25}=5.24, p<0.0001 ; \mathrm{VP}_{\mathrm{VGluT} 2}$ compared with VTA $\mathrm{GABA}_{\mathrm{GA}}$ : $q_{25}=5.75, p<0.0001 ; \mathrm{VP}_{\mathrm{VGluT} 2}$ compared with $\mathrm{VTA}_{\mathrm{DA}}: q_{25}=$ $4.36, p=0.0002 ; \mathrm{VP}_{\mathrm{VGluT} 2}$ compared with MDT: $q_{25}=2.99, p=$ 0.006; $\mathrm{VP}_{\mathrm{VGluT} 2}$ compared with LHb: $q_{25}=1.64, p=0.11$ ) and on $\mathrm{LHb}$ neurons $(A / N$ ratio $=1.55 \pm 0.3$; Tukey's multiplecomparisons tests; $\mathrm{LHb}$ compared with $\mathrm{VP}_{\mathrm{GABA}}: q_{25}=3.53, p=$ 0.002; LHb compared with $\mathrm{VTA}_{\mathrm{GABA}}: q_{25}=4.04, p=0.0005$; LHb compared with $\mathrm{VTA}_{\mathrm{DA}}: q_{25}=2.71, p=0.01$; LHb compared with MDT: $q_{25}=1.45, p=0.16$; ChR2-mediated currents are negligible at $+40 \mathrm{mV})$. In contrast, $\mathrm{VP}_{\mathrm{GABA}}$ neurons $(0.76 \pm$ $0.10, n=6)$ and GABA-like $(0.64 \pm 0.24, n=6)$ and dopaminelike $(0.91 \pm 0.29, n=5)$ VTA neurons all showed a low $A / N$ ratio and were not different from each other (Fig. 2A). MDT neurons showed intermediate $A / N$ ratio $(1.19 \pm 0.12, n=4)$, higher than in VTA and $\mathrm{VP}_{\mathrm{GABA}}$ neurons but lower than $\mathrm{VP}_{\mathrm{VGluT} 2}$ and $\mathrm{LHb}$ neurons. Thus, $\mathrm{VP}_{\mathrm{VGluT2}}$ neurons seem to have similar connections 

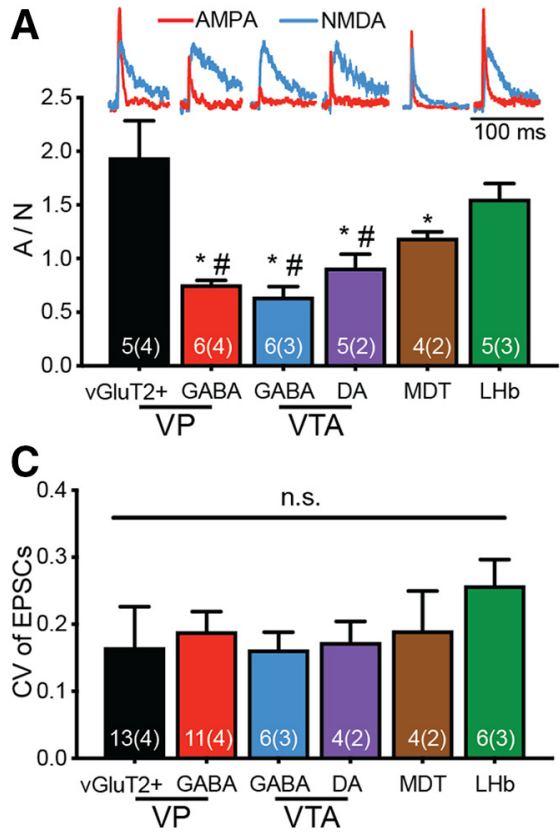

B

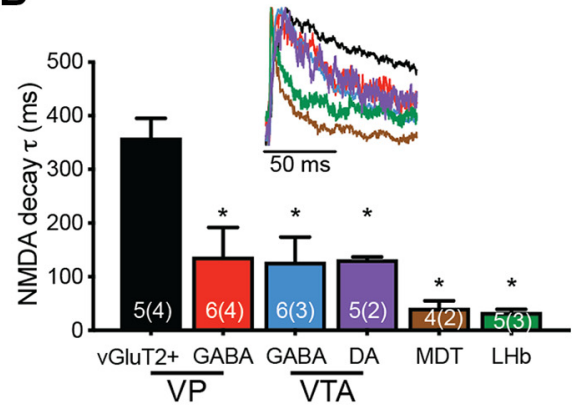

D

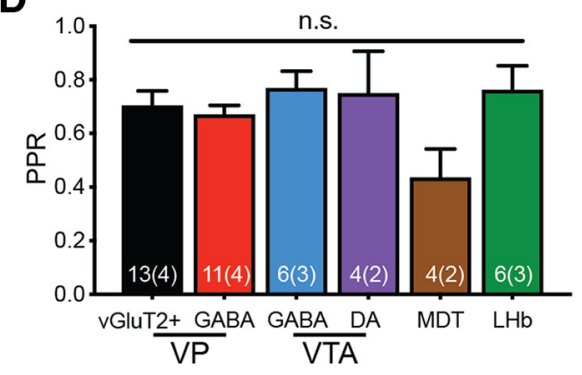

Figure 2. $\quad V_{P_{V G l u T 2}}$ neurons make the strongest synapses on $\mathrm{VP}_{\mathrm{VGluT2}}$ and $\mathrm{LHb}$ neurons based on postsynaptic, but not presynaptic, parameters. $A$, The $A / N$ ratio of $V P_{\text {VGluT2 }}$ synapses was the highest in $V P_{V G l u T 2}$ neurons and in LHb neurons [one-way ANOVA main effect of target, $F_{(5,25)}=9.63, p<0.0001 ; p<0.05$ using Tukey's post hoc multiple-comparisons test, compared with $\mathrm{VP}_{\mathrm{VGluT2}}\left(^{*}\right)$ or LHb (\#)]. Insets, Representative AMPA (red) and NMDA (blue) currents for each region. NMDA currents normalized between regions to ease comparison. $\boldsymbol{B}$, The decay time constant $(\tau)$ of the NMDA current was the slowest in $\mathrm{VP}_{\mathrm{VGluT} 2}$ neurons (one-way ANOVA main effect of target, $F_{(5,25)}=9.40, p<0.0001 ;{ }^{*} p<0.05$ using Tukey's post hoc multiple-comparisons test, comparing to $\mathrm{VP}_{\mathrm{VGluT2}}$ neurons). Inset, Representative NMDA currents from each target (normalized to peak). $C$, The CV of the EPSCS recorded at $-70 \mathrm{mV}$ did not differ between targets (one-way ANOVA, $p=0.86$ ). $\boldsymbol{D}$, The PPR recorded at $-70 \mathrm{mV}$ did not differ between targets (one-way ANOVA, $p=0.13$ ), although MDT shows a trend toward lower PPR values. Numbers in bars represent the number of cells, and the number of mice is in parentheses. n.s. = not significant.

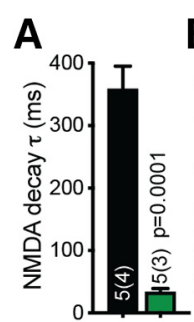

B

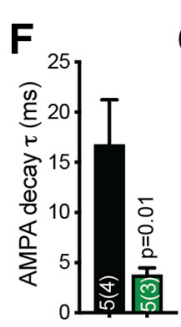

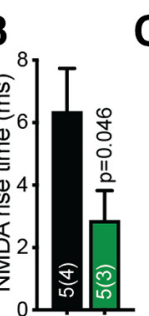

C
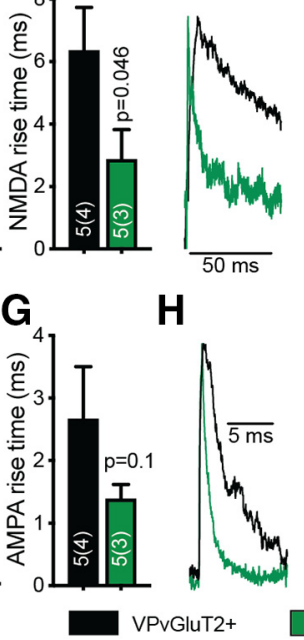
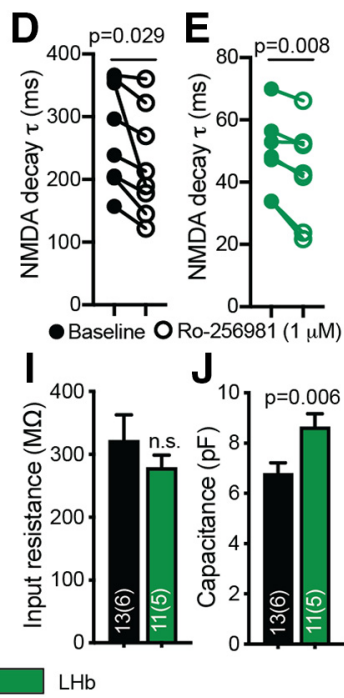

$\mathbf{J}_{10}$

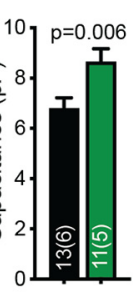

Figure 3. Differences in NMDA current kinetics between $\mathrm{VP}_{\mathrm{VGluT2}}$ and LHb neurons stem from different membrane properties and not different NMDA receptor subunit composition. $\boldsymbol{A}, \boldsymbol{B}$, Both the decay $(\boldsymbol{A})$ and rise time $(\boldsymbol{B})$ of the NMDA currents were slower in VP $\mathrm{VGluT}_{2}$ neurons compared with LHb. $\boldsymbol{C}$, Representative NMDA traces. $\boldsymbol{D}, \boldsymbol{E}$, The selective GluN2B NMDA receptor subunit antagonist Ro-256981 (1 $\mu \mathrm{M})$ decreased the NMDA decay time constant in the synapse that $\mathrm{VP}_{\mathrm{VGluT} 2}$ neurons make on both $\mathrm{VP}_{\mathrm{VGluT} 2}$ neurons (average decrease of $47.7 \pm 17.4 \mathrm{~ms}$, which represents $\sim 17.8 \%$ decrease) and LHb neurons (average decrease of $6.0 \pm 4 \mathrm{~ms}$, which represents $14.6 \%$ decrease). $\boldsymbol{F}, \mathbf{G}$, The decay $(\boldsymbol{F})$ of the AMPA currents was slower in VP $\mathrm{VGluT}_{2}$ neurons compared with $\mathrm{LHb}$ neurons; the rise time was not different between the two cell populations $(\boldsymbol{G})$. $\boldsymbol{H}$, Representative AMPA traces. $\boldsymbol{I}, \boldsymbol{J}$, The membrane input resistance $(\boldsymbol{I})$ did not differ between $V P_{V G l u T 2}$ and $L H b$ neurons, but the capacitance $(\boldsymbol{J})$ was significantly higher in $L H b$ neurons. $\boldsymbol{D}, \boldsymbol{E}$, Paired or unpaired two-tailed Student's $t$ tests were used. n.s. = not significant. with the aversion-related $\mathrm{VP}_{\mathrm{VGluT} 2}$ and $\mathrm{LHb}$ neurons, presumably making stronger excitatory synapses on these specific regions compared with the other targets tested here.

As indicated above, we interpret the high $A / N$ ratios in the $\mathrm{LHb}$ and $\mathrm{VP}_{\mathrm{VGluT}}$ synapses as indicating that these synapses are stronger than the others (i.e., have more postsynaptic AMPA receptors). However, the $A / N$ ratio measure may be affected by other factors that should be considered when interpreting the results. For example, differences in the size of the dendritic arbor or the passive membrane properties between the different neurons could affect the $A / N$ ratio (Bar-Yehuda and Korngreen, 2008; Williams and Mitchell, 2008). Such differences would change both the quality of the voltage clamp in distant synapses (i.e., the space clamp) and the recovery of dendritic currents in the soma. Moreover, these factors have a different effect on AMPA and NMDA currents measured at the soma due to their different kinetics and voltage dependence. Therefore, the sensitivity of the $A / N$ ratio to the basic parameters of the different neurons should be considered when interpreting the data.

It is also possible that the differences in $A / N$ ratio stem from differences in NMDA receptor function rather than AMPA receptor function. One possible difference may be the proportion of NMDA receptors expressing the GluN2B subunit. This should be reflected as slower current decays and may indicate an increase in the proportion of extrasynaptic NMDA receptors, as GluN2B-expressing NMDA receptors tend to localize outside of the synapse (Hardingham and Bading, 2010; Gladding and Raymond, 2011; Paoletti et al., 2013; Naassila and Pierrefiche, 2019). Indeed, our data reveal that the $\mathrm{VP}_{\mathrm{VGluT2}} \rightarrow$ $\mathrm{VP}_{\text {VGluT2 }}$ synapse shows the slowest NMDA decay time constants (359 $\pm 82 \mathrm{~ms}$ ) compared with all other targets [Fig. 2B; one-way ANOVA, main group (projection) effect, $F_{(5,25)}=9.40, p<$ 0.0001; Tukey's multiple-comparisons tests; $\mathrm{VP}_{\mathrm{VGluT} 2}$ compared with $\mathrm{VP}_{\mathrm{GABA}}: q_{25}=5.98, p=0.004$; $\mathrm{VP}_{\mathrm{VGluT} 2}$ compared with $\mathrm{VTA}_{\mathrm{GABA}}: q_{25}=6.52, p=0.002 ; \mathrm{VP}_{\mathrm{VGluT} 2}$ compared with $\mathrm{VTA}_{\mathrm{DA}}: q_{25}=6.12, p=0.003$; $\mathrm{VP}_{\mathrm{VGluT} 2}$ compared with MDT: $q_{25}=8.06, p=0.001 ; \mathrm{VP}_{\mathrm{VGluT} 2}$ compared with LHb: $q_{25}=8.25$, $p<0.0001]$. The LHb, in contrast, showed the fastest NMDA decay (33.6 $\pm 11.2 \mathrm{~ms})$, which was an order of magnitude slower than that seen in $\mathrm{VP}_{\mathrm{VGluT} 2} \rightarrow \mathrm{VP}_{\mathrm{VGluT} 2}$ synapses (Fig. 3A-C).

A possible interpretation, as discussed above, is a higher proportion of GluN2B-expressing NMDA receptors in $\mathrm{VP}_{\mathrm{VGluiT2iT2}}$ neurons compared with LHb. However, differences in current decay time courses could also reflect differences in the properties of the membrane or in the location of the synapse (distance from the soma). To further examine the cause for the difference in NMDA decay between the $\mathrm{VP}_{\mathrm{VGluT} 2} \rightarrow \mathrm{VP}_{\mathrm{VGluT} 2}$ and $\mathrm{VP}_{\mathrm{VGluT} 2} \rightarrow$ LHb synapses (Fig. $3 A$; unpaired $t$ test, $t_{(8)}=7.76, p=0.0001$ ), we first examined the effect of the specific inhibitor of GluN2Bexpressing NMDA receptors, Ro-256981 ( $1 \mu \mathrm{M})$, on NMDA currents in $\mathrm{VP}_{\text {VGluT2 }}$ and $\mathrm{LHb}$ neurons. We found that Ro-256981 decreased the NMDA decay time constant in both synapses (Fig. 
$3 D, E$; paired $t$ tests; $\mathrm{VP}_{\mathrm{VGluT} 2}: t_{(7)}=2.74$, $p=0.029$; LHb: $\left.t_{(6)}=3.92, p=0.008\right)$. When examining the rise time of NMDA currents (Fig. $3 B$ ) and the kinetics of AMPA currents (Fig. $3 F-H$ ), both of which are not sensitive to the expression of GluN2B, we found that the NMDA rise time and AMPA decay were significantly slower in $\mathrm{VP}_{\mathrm{VGluT2}}$ neurons (NMDA rise times: $\mathrm{VP}_{\mathrm{VGluT} 2}, 6.35 \pm 3.1 \mathrm{~ms}$; LHb, $2.86 \pm 1.92 \mathrm{~ms}$; unpaired $t$ test, $t_{(7)}=1.95$, $p=0.046$; AMPA decay times: $\mathrm{VP}_{\mathrm{VGluT2}}$, $16.75 \pm 10.04 \mathrm{~ms} ; \mathrm{LHb}, 3.774 \pm 1.59 \mathrm{~ms}$; unpaired $t$ test, $t_{(7)}=2.86, p=0.01$ ). These data imply that the difference in the NMDA current decay time constant between $\mathrm{VP}_{\mathrm{VGluT} 2} \rightarrow \mathrm{VP}_{\mathrm{VGluT} 2}$ and $\mathrm{VP}_{\mathrm{VGluT} 2}$ $\rightarrow$ LHb synapses is not due to the difference in GluN2B expression but is because of differences in membrane properties. This hypothesis is supported by the fact that the membrane capacitance (but not input resistance) was different between $\mathrm{VP}_{\mathrm{VGluT2}}$ and LHb neurons (Fig. 3 I, J; unpaired $t$ test, $\left.t_{(22)}=2.75, p=0.006\right)$.

The postsynaptic analysis gives only one aspect of the synapse. Do the $\mathrm{VP}_{\mathrm{V}^{-}}$ GluT2 terminals in the different targets differ in the probability of presynaptic neurotransmitter release? To examine this, we applied (at $-70 \mathrm{mV}$ ) two consecutive stimulations (50 $\mathrm{ms}$ interval) and measured the ratio between the amplitudes of the second and the first pulse [paired-pulse ratio (PPR)] and the coefficient of variation (CV) of the current amplitudes in the first stimulation. Differences in these two measures (under certain assumptions; Faber and Korn, 1991) are considered to reflect a presynaptic mechanism, with stronger synapses correlating with decreased $\mathrm{PPR}$ and $\mathrm{CV}$ (Berninger et al., 1999; Schinder et al., 2000). Our data demonstrate that there was no significant difference in the PPR or $\mathrm{CV}$ between the six examined synapses [Fig. 2C,D; one-way ANOVA tests; PPR: main group (projection) effect, $F_{(5,25)}=1.84$, $p=0.13$; CV: main group (projection) effect, $F_{(5,25)}=0.38, p=$ $0.86]$. Therefore, we conclude that in drug-naive animals, $\mathrm{VP}_{\mathrm{VGluT2}}$ neurons may be more strongly connected with each other and the $\mathrm{LHb}$ than with other regions, and that this is driven by postsynaptic, and not presynaptic, mechanisms.

\section{LHb and $\mathrm{VP}_{\mathrm{VGluT2}}$ neurons have the largest proportion of VP $_{\text {VGluT2 }}$ input}

The experiments so far show that the strongest synapses the $\mathrm{VP}_{\mathrm{V}^{-}}$ GluT2 neurons make may be on $\mathrm{VP}_{\mathrm{VGluT2}}$ and LHb neurons. However, this experimental design does not tell how dominant the $\mathrm{VP}_{\mathrm{VGluT2}}$ input (of the total glutamatergic input) to the LHb or to the other targets examined here is. To tackle this question, we used spontaneous EPSCs (sEPSCs) as a reporter of the total glutamatergic synaptic inputs on a specific neuron. We hypothesized that in regions in which the $\mathrm{VP}_{\mathrm{VGluT2}}$ input makes a sub-

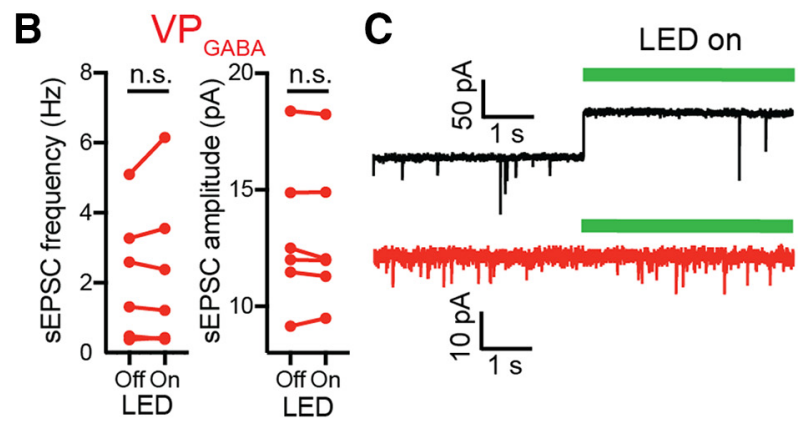

E

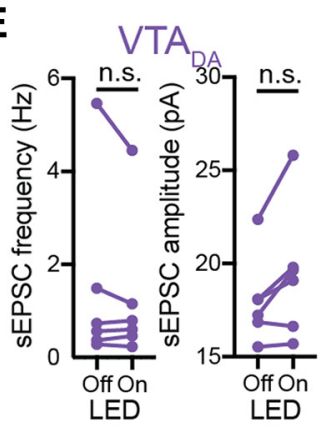

$\mathbf{F}$
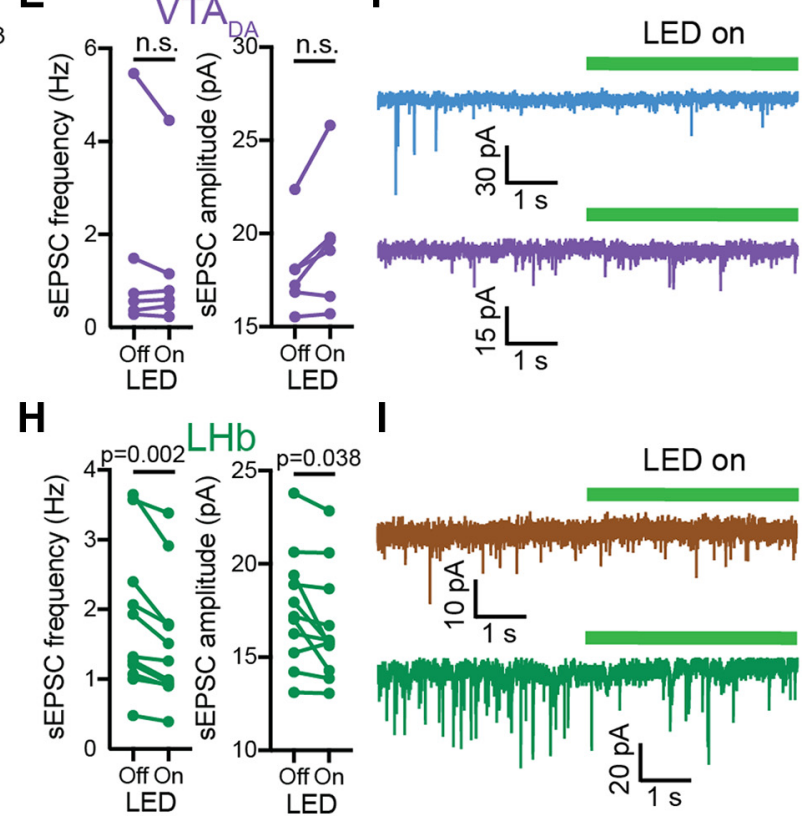

I

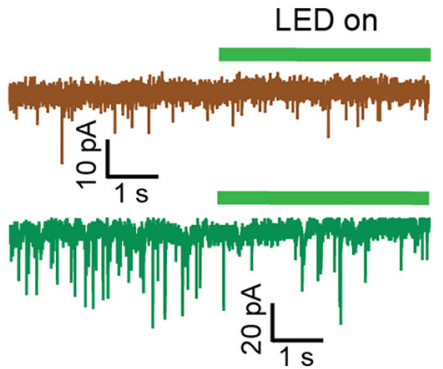

Figure 4. $L \mathrm{LHb}, \mathrm{VP}_{\mathrm{VGluT2}}$, and $\mathrm{VTA}_{\mathrm{GABA}}$ neurons are the most sensitive to $\mathrm{VP}_{\mathrm{VGluT} 2}$ input. Recordings were performed as in Figure picrotoxin $(50 \mu \mathrm{m})$ before ( $4 \mathrm{~s})$ and during $(4 \mathrm{~s})$ the activation of ArchT using a $560 \mathrm{~nm}$ LED. $A-C$, Effect in the VP. $A$, Inhibiting the input significantly decreased the sEPSC frequency but not amplitude in $\mathrm{VP}_{\mathrm{VGluT}}$ neurons. $\boldsymbol{B}$, No effect was seen in $\mathrm{VP}_{\mathrm{GAB}}$ the recorded cell was infected with ArchT). D-F Effect in the VTA. Inhibiting th VP the frequency and amplitude of sEPSCs in the LHb. I, Representative traces for MDT and LHb recordings. All statistical tests are paired Student's $t$ tests. n.s. $=$ not significant.

stantial proportion of the total glutamatergic input, selective optogenetic inhibition of the $\mathrm{VP}_{\mathrm{VGluT} 2}$ terminals should result in a decrease in the frequency of sEPSCs. We infected $\mathrm{VP}_{\mathrm{VGluT2}}$ neurons with the inhibitory opsin ArchT in a Cre-dependent manner and recorded sEPSCs from the six targets depicted in Figure 1. In each neuron, we turned on [4 s (not long enough to cause changes in $\mathrm{pH}$ ); Mahn et al., 2016] and off (8 s) the LED alternately and measured the amplitude and frequency of sEPSCs in each episode (Fig. 4). Our recordings revealed that the only targets that showed a decrease in sEPSC frequency when inhibiting the $\mathrm{VP}_{\mathrm{VGluT2}}$ terminals were the same ones that showed the highest $A / N$ ratios - the $\mathrm{LHb}$ and $\mathrm{VP}_{\mathrm{VGluT}}$ neurons (Fig. $4 A, C, H, I$; paired $t$ tests; $\mathrm{VP}_{\mathrm{VGluT} 2}: t_{(7)}=2.55, p=0.038$; LHb: $t_{(10)}=4.32, p=0.002$ ). Interestingly, inhibiting $\mathrm{VP}_{\mathrm{VGluT2}}$ terminals also affected sEPSC amplitude, decreasing it in $\mathrm{VTA}_{\mathrm{GABA}}$ neurons (paired $t$ test, $t_{(9)}=3.11, p=0.013$ ) and in the LHb (paired $t$ test, $t_{(10)}=2.39, p=0.038$; Fig. $\left.4 D, H\right)$. This may mean that, in these two cell populations, the $\mathrm{VP}_{\mathrm{VGluT} 2}$ currents are larger than the 
Table 1. A/N ratios, NMDA current decay time constants $(\tau)$, CVs of EPSCs at $-70 \mathrm{mV}$, and PPRs in six targets of VP ${ }_{\mathrm{VGluT2}}$ neurons in saline and cocaine-withdrawn mice

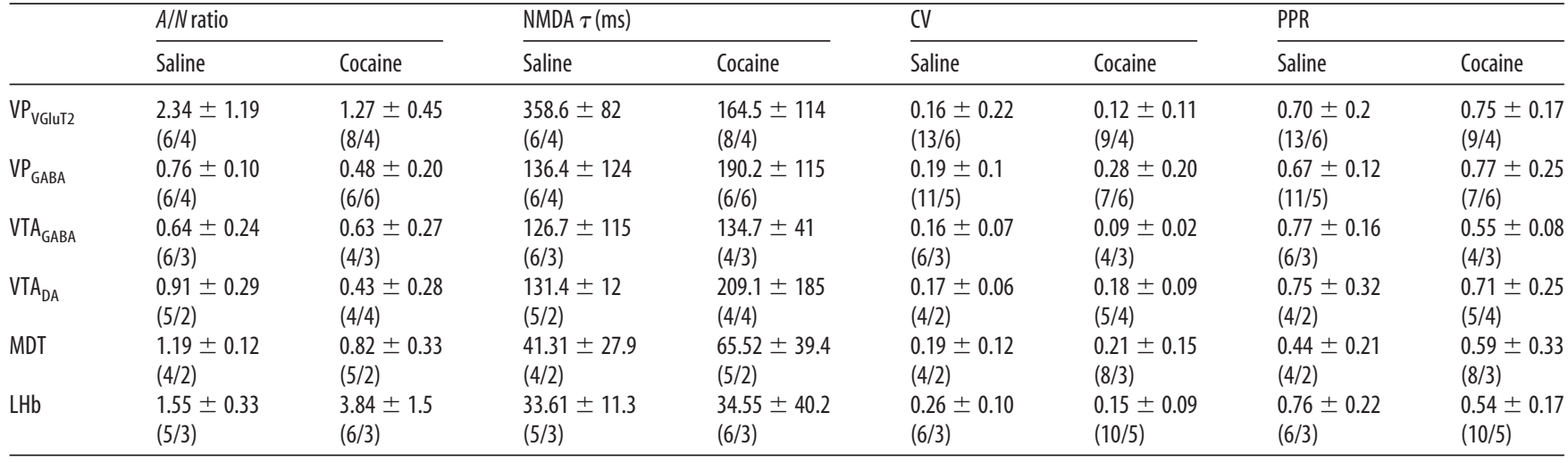

Numbers in parentheses represent the number of cells/number of mice.

average glutamatergic current, possibly indicating they are closer to the soma than other glutamatergic synapses. Note that in VTA $_{\text {GABA }}$ neurons, the decrease in sEPSC amplitude was not accompanied by a decrease in the average frequency. A possible explanation is that, although the $\mathrm{VP}_{\mathrm{VGluT} 2}$ input is among the biggest in amplitude in most $\mathrm{VTA}_{\mathrm{GABA}}$ neurons, the effect of this input on the frequency of the total spontaneous excitatory events was not consistent between cells. Also note that, although not significant (paired $t$ test, $t_{(5)}=2.51, p=0.054$ ), most $\mathrm{VTA}_{\mathrm{DA}}$ neurons showed an increase in sEPSC amplitude, exactly opposite to the effect seen in $\mathrm{VTA}_{\mathrm{GABA}}$ neurons. This may relate to the opposite behavioral roles of $\mathrm{VTA}_{\mathrm{GABA}}$ and $\mathrm{VTA}_{\mathrm{DA}}$ neurons in drug seeking. Overall, the data suggest not only that $\mathrm{VP}_{\mathrm{VGluT2}}$ neurons predominantly activate $\mathrm{LHb}$ and $\mathrm{VP}_{\mathrm{VGluT} 2}$ neurons, but that these two targets, possibly together with $\mathrm{VTA}_{\mathrm{GABA}}$ neurons, respond predominantly to $\mathrm{VP}_{\mathrm{VGluT2}}$ input among all other inputs (compared with the other cell types examined here). This is particularly interesting given that these targets, and not the others we examined, are known to encode aversion.

\section{$\mathrm{VP}_{\mathrm{VGluT2}}$ synapses specifically on LHb and $\mathrm{VTA}_{\mathrm{GABA}}$ neurons are strengthened after cocaine CPP and abstinence}

Withdrawal is classically accompanied by increased craving for the drug (Lu et al., 2004) and negative feelings (which may drive the craving for the drug; Breese et al., 2005; Chavkin and Koob, 2016). $\mathrm{VP}_{\mathrm{VGluT} 2}$ neurons have recently been shown to induce avoidance when activated and, specifically, their projection to the LHb (Faget et al., 2018; Tooley et al., 2018). Therefore, we examined whether cocaine CPP followed by abstinence alters the aversive $\mathrm{VP}_{\mathrm{VGluT2}} \rightarrow \mathrm{LHb}$ pathway as well as all other pathways depicted in Figure 1. Mice were trained on a cocaine CPP task for 2 weeks, followed by 2 weeks of abstinence (control mice were given only saline; Fig. $5 A$ ). After the last day of abstinence, mice were either tested on the CPP task to ensure motivation for cocaine (CPP score was $0.40 \pm 0.26$ for cocaine mice and $-0.07 \pm$ 0.25 for saline mice; one-sample $t$ test, comparing to a CPP score of $0, t_{(9)}=4.88, p=0.0009$ and $t_{(6)}=0.78, p=0.47$ for cocaine and saline mice, respectively) or killed for slice recordings. Examination of the $A / N$ ratio showed a striking difference between the $\mathrm{VP}_{\mathrm{VGluT} 2} \rightarrow \mathrm{LHb}$ projection and all other projections. Most of the $\mathrm{VP}_{\mathrm{VGluT2}}$ synapses were depressed after CPP and abstinence. This includes the projections to $\mathrm{VP}_{\mathrm{VGluT2}}$ (unpaired $t$ test, $t_{(12)}=2.35$, $p=0.037$ ), $\mathrm{VP}_{\mathrm{GABA}}$ (unpaired $t$ test, $t_{(10)}=2.98, p=0.014$ ), and VTA $_{\mathrm{DA}}$ neurons (unpaired $t$ test, $t_{(7)}=2.51, p=0.04$; MDT neurons showed a nonsignificant decrease in $A / N$ ratio; unpaired $t$ test, $\left.t_{(7)}=2.14, p=0.07\right)$. Thus, it seems that abstinence from cocaine depresses, in general, the output of $\mathrm{VP}_{\mathrm{VGluT2}}$ neurons and, therefore, their ability to recruit their postsynaptic targets. In contrast, the $\mathrm{VP}_{\mathrm{VGluT2}} \rightarrow \mathrm{LHb}$ synapse, despite already being the strongest output of $\mathrm{VP}_{\mathrm{VGluiT2}}$ neurons, was further strengthened after abstinence $(A / N$ ratio increased from $1.55 \pm 0.3$ to $3.72 \pm 1.3$; unpaired $t$ test, $t_{(9)}=3.29, p=0.009$; Fig. 5 ; Table 1 ). Therefore, the coupling between $\mathrm{VP}_{\mathrm{VGluT} 2}$ neurons and the $\mathrm{LHb}$ seems to become tighter after cocaine CPP and abstinence. The decay of the NMDA currents in all synapses but the $\mathrm{VP}_{\mathrm{VGluT} 2} \rightarrow$ $\mathrm{VP}_{\mathrm{VGluT} 2}$ synapse did not change after abstinence from cocaine, suggesting that the changes in $A / N$ ratio are likely due to changes in AMPA receptor function. Collectively, these data show that after cocaine CPP and abstinence, synaptic plasticity occurs not only in the reward-related $\mathrm{VP}_{\mathrm{GABA}}$ neurons (Creed et al., 2016; Heinsbroek et al., 2017b) but also in the avoidance-related $\mathrm{VP}_{\text {VGluT2 }}$ neurons.

Examination of the effect of cocaine CPP and abstinence on presynaptic parameters of $\mathrm{VP}_{\mathrm{VGluT2}}$ synapses in the different targets revealed a somewhat similar pattern of changes, but with an intriguing difference. As with $A / N$ ratio, the $\mathrm{VP}_{\mathrm{VGluT} 2} \rightarrow \mathrm{LHb}$ synapse was also strengthened presynaptically after cocaine CPP and abstinence, indicated by the decrease in both the CV and PPR of the evoked EPSCs (Fig. $5 K, L$; paired $t$ tests; CV: $t_{(14)}=2.29$, $p=0.038$; PPR: $\left.t_{(14)}=2.23, p=0.042\right)$. Unlike the $A / N$ ratio measurements, abstinence from cocaine strengthened the presynaptic probability of transmitter release also in the $\mathrm{VP}_{\mathrm{VGluT} 2} \rightarrow$ $\mathrm{VTA}_{\mathrm{GABA}}$ synapse, as indicated by the decrease in both CV and PPR (Fig. $5 H-$ J; paired $t$ tests; CV: $t_{(8)}=2.39, p=0.047$; PPR: $t_{(8)}$ $=2.46, p=0.039)$. This is intriguing because, from all targets examined here, the $\mathrm{LHb}$ and $\mathrm{VTA}_{\mathrm{GABA}}$ are the ones that, like the $\mathrm{VP}_{\text {VGluT2 }}$ neurons themselves, are classically linked to aversion (Tan et al., 2012; van Zessen et al., 2012; Baker et al., 2016; Meye et al., 2016; Morales and Margolis, 2017). All other targets of the $\mathrm{VP}_{\text {VGluT2 }}$ neurons did not show any change in the probability of presynaptic release. When comparing the changes specifically in the VTA, contrasting effects emerge between the excitatory input from the VP to the GABAergic and dopaminergic neuronswhereas the excitatory drive to the dopaminergic neurons is depressed postsynaptically (Fig. 5E), the input to the GABAergic neurons, which themselves inhibit dopaminergic neurons, is potentiated presynaptically (Fig. $5 H, I$ ). This would lead to stronger suppression of dopamine release when the $\mathrm{VP}_{\mathrm{VGluT} 2} \rightarrow \mathrm{VTA}$ pathway is activated. Moreover, this local action of $\mathrm{VP}_{\mathrm{VGluT}}$ inputs in the VTA to suppress dopamine release would be supplemented by the enhanced recruitment of LHb neurons [which suppress dopamine release (Graziane et al., 2018)] and decreased 
A

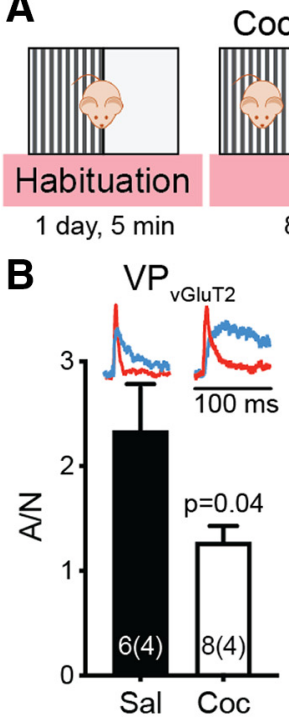

C

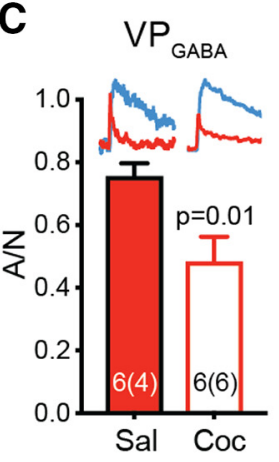

H

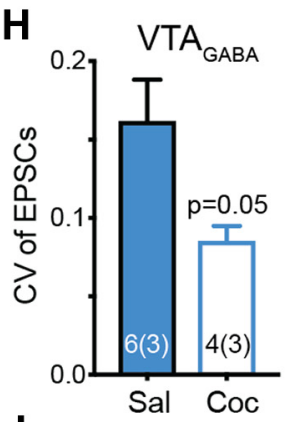

I

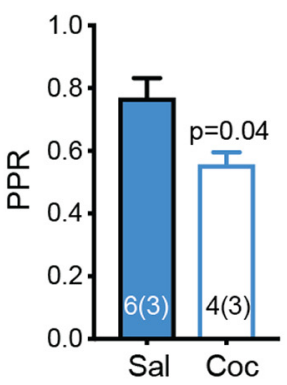

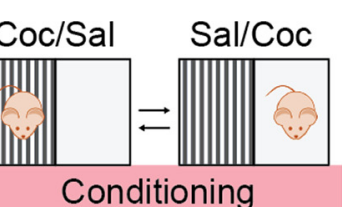

8 days, $15 \mathrm{~min} /$ day

D $\quad V_{T A} A_{\text {GABA }}$

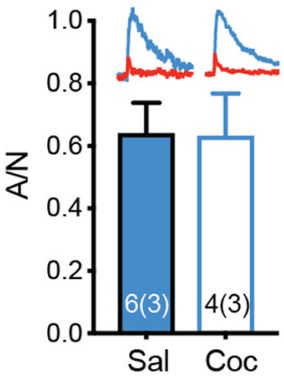

E
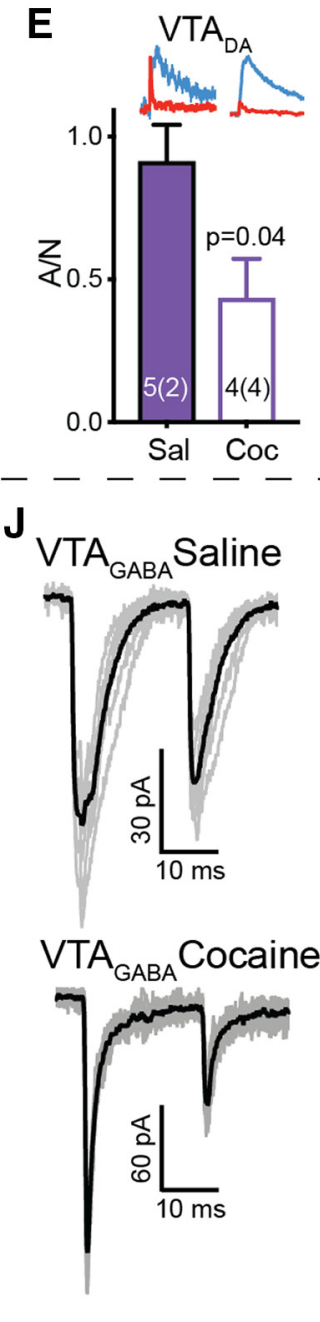
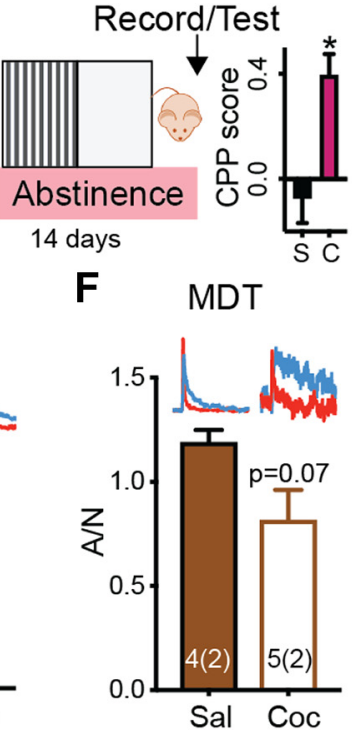

G
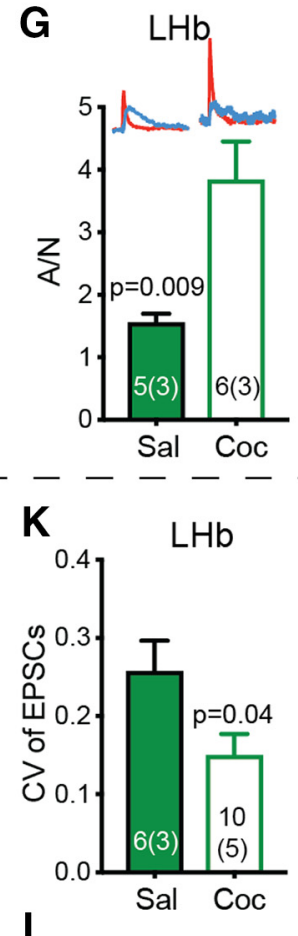

L

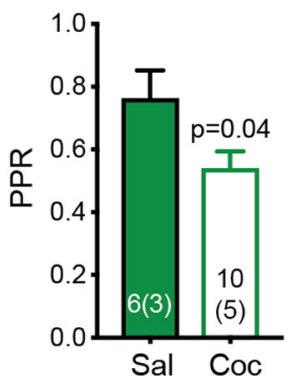

Figure 5. Cocaine CPP and abstinence strengthen $V P_{V G I u T 2}$ input to the $L H b$ and $V T A_{G A B A}$ neurons but weaken input to all other targets. $\boldsymbol{A}$, Left, Timeline of the (PP protocol (from left to right). Mice were habituated to the arena on the first day and then received eight alternating intraperitoneal injections of either cocaine $(15 \mathrm{mg} / \mathrm{kg}$ ) or saline, one injection per day. Control (cocainenaive) mice received only saline injections. Cocaine was paired with one of the sides, and saline was given on the other side. After conditioning, mice went through $14 \mathrm{~d}$ of abstinence from cocaine and then were either tested for preference or used for electrophysiological recordings. Right, Preference for the cocaine-paired side in the cocaine group $(C)$ was significantly higher than zero (one-sample $t$ test, $(P P$ score $0.39 \pm 0.26, p=0.0009)$ and different from the saline $(S)$ group $(p=0.0019)$. $\boldsymbol{B}$ - $\mathbf{G}$, Postsynaptic effects. $A / N$ ratios in each target of $\mathrm{VP}_{\mathrm{VGluT} 2}$ neurons in saline (full bars) and cocaine-abstinent (open bars) mice. $\boldsymbol{B}-\boldsymbol{F}$, Cocaine CPP

recruitment of $\mathrm{VP}_{\mathrm{GABA}}$ neurons [which disinhibit dopamine neurons in the VTA (Hjelmstad et al., 2013; Leung and Balleine, 2015)]. Overall, our data show that cocaine $\mathrm{CPP}$ and abstinence change $\mathrm{VP}_{\mathrm{VGluT2}}$ outputs such that synapses on targets that are known to decrease dopamine release are strengthened, whereas other pathways to targets that enhance dopamine release are weakened.

\section{Discussion}

Our work is the first to describe the nature of the connectivity of $\mathrm{VP}_{\mathrm{VGluT2}}$ neurons with multiple targets and how these projections are affected differentially after cocaine CPP and abstinence. We first show that $\mathrm{VP}_{\mathrm{VGluT2}}$ neurons may make different synapses on different targets, with preference for aversion-related targetsthe $\mathrm{LHb}$ and $\mathrm{VP}_{\mathrm{VGluT} 2}$ neurons receive the strongest inputs. These differences between targets are driven by postsynaptic, and not presynaptic, mechanisms (Fig. 2). Moreover, from the perspective of the receiving target region, we found that the $\mathrm{LHb}, \mathrm{VP}_{\mathrm{VGluT} 2}$, and $\mathrm{VTA}_{\mathrm{GABA}}$ neurons, all aversion related, seem to be the regions with the highest sensitivity to $\mathrm{VP}_{\mathrm{VGluT}}$ input and changes therein (Fig. 4). Finally, cocaine CPP and abstinence have specifically strengthened the projections of $\mathrm{VP}_{\text {VGluT2 }}$ neurons to $\mathrm{LHb}$ and $\mathrm{VTA}_{\mathrm{GABA}}$ neurons, both major players in the emerging network that encodes aversion. This is in stark contrast to the general weakening of the synapses that $\mathrm{VP}_{\mathrm{VGluT2}}$ neurons make on all other targets tested here$\mathrm{VP}_{\mathrm{VGluT2}}, \mathrm{VP}_{\mathrm{GABA}}, \mathrm{VTA}_{\mathrm{DA}}$, and MDT. Overall, our data demonstrate the diverse connections $\mathrm{VP}_{\mathrm{VGluT} 2}$ neurons make with different targets and the target-dependent changes occurring after cocaine CPP and abstinence, with preferred potentiation of synapses onto aversion-related neurons.

$\leftarrow$

and abstinence decreased the $A / N$ ratio in $\mathrm{VP}_{\mathrm{VGluT} 2}(\boldsymbol{B}), \mathrm{VP}_{\mathrm{GABA}}$ $(\boldsymbol{C})$, and $\mathrm{VTA}_{\mathrm{DA}}(\boldsymbol{E})$; generated a nonsignificant decrease in MDT neurons $(p=0.07 ; \boldsymbol{F})$; and did not affect the $A / N$ ratio in $\mathrm{VTA}_{\mathrm{GABA}}$ neurons (D). $\boldsymbol{G}$, In contrast, cocaine (PP and abstinence significantly increased the $A / N$ ratio in the $\mathrm{LHb}$ by more than twofold, from $1.55 \pm 0.3$ to $3.84 \pm 1.5$. Insets, Representative AMPA (red) and NMDA (blue) currents for each region. NMDA currents normalized between regions to ease comparison. $\boldsymbol{H}-\boldsymbol{L}$, Presynaptic effects. $\mathbf{C}_{0}-$ caine (PP and abstinence decreased the coefficient of variation of evoked EPSCS (CV) and the PPR in both VTA GABA $_{\text {A }}$ $(\boldsymbol{H}-\boldsymbol{J})$ and $\mathrm{LHb}(\boldsymbol{K}-\boldsymbol{L})$ neurons. $\boldsymbol{J}$, Representative traces for the presynaptic effects of abstinence from cocaine on $\mathrm{VP}_{\mathrm{V}}$ GluT2 input to VTA $\mathrm{VABA}_{G}$ neurons. All statistical tests are unpaired Student's $t$ tests. The asterisk indicates $p<0.05$ when comparing to zero using a one-sample $t$-test. 
A

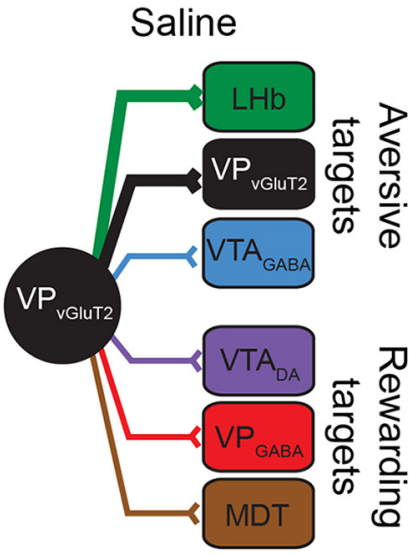

B

AMPA receptor

Aversive targets
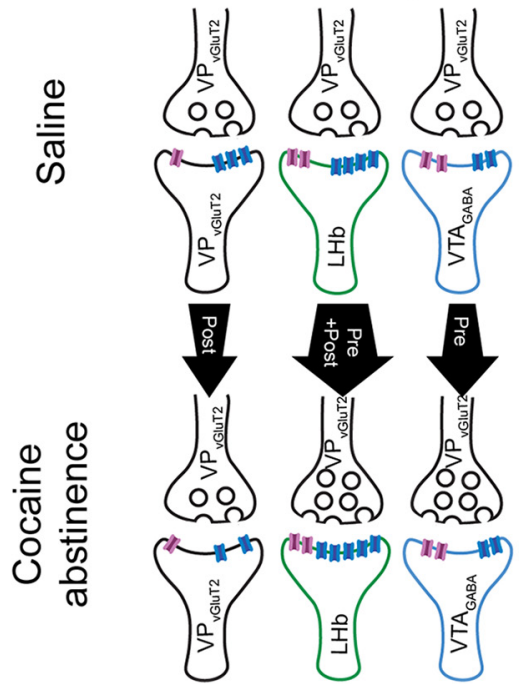

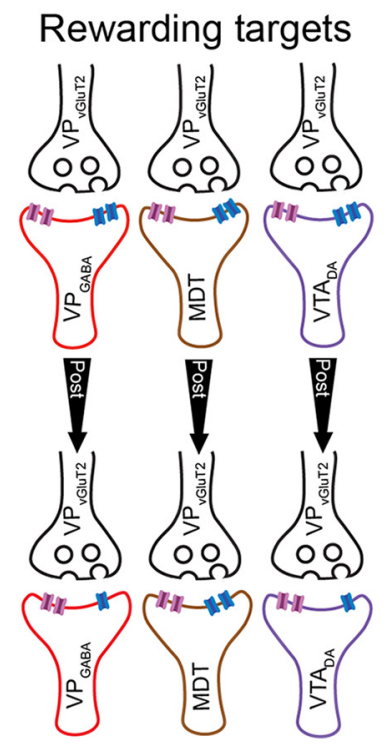

Figure 6. Changes in $\mathrm{VP}_{\mathrm{VGluT}}$ synapses after cocaine $\mathrm{CPP}$ and abstinence. $A$, System level. Drawings are arranged such that synapses on aversive targets are on top $\left(\mathrm{VP}_{\mathrm{VGluT} 2}, \mathrm{LHb}, \mathrm{VTA}_{\mathrm{GABA}}\right)$ and synapses on rewarding $\left(\mathrm{VP}_{\mathrm{GABA}}, V_{T A} A_{D A}\right)$ or neutral (MDT) targets are at the bottom. Left, Saline mice. VP $\mathrm{VGluT}_{2}$ neurons make the strongest synapses on each other and on LHb neurons. Right, After cocaine CPP and abstinence. The synapses of $\mathrm{VP}_{\mathrm{VGluT}}$ neurons on $\mathrm{LHb}$ and $\mathrm{VTA}_{\mathrm{GABA}}$ are strengthened, whereas synapses on all rewarding targets are weakened. The synapse on MDT does not seem to change. $\boldsymbol{B}$, Hypothesized synaptic mechanisms. Top, Saline. Bottom, After cocaine CPP and abstinence. Width of arrows at their bases and ends reflects the strength of the synapse in control and after abstinence, respectively. Saline mice, $V P_{V G \mid{ }_{T 2}}$ synapses on each other and on $L H b$ neurons show the highest number of AMPA receptors (based on highest AMPA/NMDA ratios) compared with the inputs to the VTA, MDT, and $\mathrm{VP}_{\mathrm{GABA}}$ neurons. Presynaptic parameters (represented in the drawing by the number of vesicles in the terminal) are similar between synapses. After abstinence, synapses on aversive targets (except VP $\mathrm{VGluT2}_{2}$ neurons) are potentiated, either presynaptically $\left(V_{T A} A_{G A B A}\right)$ or both presynaptically and postsynaptically (LHb). Synapses on other $\mathrm{VP}_{\mathrm{VGluT} 2}$ neurons seem to weaken. All synapses on reward targets are depressed through a postsynaptic mechanism (fewer postsynaptic AMPA receptors).

The local connectivity of $\mathrm{VP}_{\mathrm{VGluT} 2}$ neurons

The $\mathrm{VP}_{\mathrm{VGluT} 2}$ neurons are scarcely distributed in the $\mathrm{VP}$ (only 29 cells per $10^{7} \mu \mathrm{m}^{3}$ tissue; Hur and Zaborszky, 2005) and thus represent a minority of the neurons in the VP. Their difference from the GABAergic majority is reflected not only by the neurotransmitter they release but also in their behavioral role, as they induce aversion whereas $\mathrm{VP}_{\mathrm{GABA}}$ neurons encode reward (Faget et al., 2018; Richard et al., 2018). This dissimilarity between the two cell populations raises the question of how well they are interconnected. For example, VGluT2-expressing neurons in the VTA, which themselves are a minority in the VTA, were shown to make connections both on each other and on other non-VGluT2 neurons (Dobi et al., 2010). Our data show that, as in the VTA,
$\mathrm{VP}_{\mathrm{VGluT2}}$ neurons make synaptic connections both on each other and on $\mathrm{VP}_{\mathrm{GABA}}$ neurons. However, the features of these two inputs are different. The parameters of the $\mathrm{VP}_{\mathrm{VGluT} 2}$ input to $\mathrm{VP}_{\mathrm{GABA}}$ neurons are more similar to those of the input to VTA or MDT neurons than to $\mathrm{VP}_{\mathrm{VGluT2}} \rightarrow$ $\mathrm{VP}_{\mathrm{VGluT2}}$ synapses. This is evident from the $A / N$ ratio, NMDA decay time constant (Fig. 2), proportion of excitatory input (Fig. 4), and effect of cocaine CPP and abstinence (Fig. 5). Such robust difference suggests that $\mathrm{VP}_{\mathrm{VGluT2}}$ neurons may form an independent network in the VP, and that for them, $\mathrm{VP}_{\mathrm{GABA}}$ neurons may represent a "different region." In fact, as is discussed below, $\mathrm{VP}_{\mathrm{VGluT2}}$ neurons may be functionally better described as part of an aversive network of the brain, even though anatomically they reside within the "rewarding" VP. To make a stronger statement in this direction, further characterization of the $\mathrm{VP}_{\mathrm{GABA}}$ input to $\mathrm{VP}_{\mathrm{VGluT2}}$ neurons needs to be established to examine whether this $\mathrm{VP}_{\mathrm{VGluT} 2}$ internal network is modulated by $\mathrm{VP}_{\mathrm{GABA}}$ neurons or is really independent of the general VP activity.

\section{$\mathrm{VP}_{\mathrm{VGluT2}}$ neurons and addiction to cocaine}

The VP is known to be involved in addiction to cocaine (Smith et al., 2009; Root et al., 2015) and to show synaptic plasticity after withdrawal (Kupchik et al., 2014; Creed et al., 2016). Here, we show that, specifically, the $\mathrm{VP}_{\mathrm{VGluT2}}$ neurons show substantial changes in their synaptic activity after cocaine CPP and abstinence. These changes include strengthening of their synapses on $\mathrm{LHb}$ and $\mathrm{VTA}_{\mathrm{GABA}}$ neurons while depressing the synapses on $\mathrm{VP}$ and $\mathrm{VTA}_{\mathrm{DA}}$ neurons. This is predicted to result in decreased probability of dopamine release (as discussed below) and increased activation of the aversion-related $\mathrm{LHb}$ and $\mathrm{VTA}_{\mathrm{GABA}}$ neurons. Importantly, although these results clearly indicate that $\mathrm{VP}_{\mathrm{VGluT2}}$ neurons are affected by our behavioral protocol, whether the observed changes were induced by the mere exposure to cocaine, the learning of the CPP task, the abstinence from cocaine, or a combination of these options remains to be explored.

It is also important to note that, although this study focuses on the outputs of $\mathrm{VP}_{\mathrm{VGluT2}}$ neurons, the inputs to these neurons may be as important. $\mathrm{VP}_{\mathrm{VGluT2}}$ neurons receive both glutamatergic and GABAergic inputs from, among others, the nucleus accumbens, medial prefrontal cortex, and amygdala (Tooley et al., 2018). It is still unknown whether and how these inputs change after withdrawal from cocaine, but considering that the excitatory drive to the NAc is potentiated after withdrawal (Gipson et al., 2013), it is reasonable to predict that NAc GABA input to 
the VP, including to $\mathrm{VP}_{\mathrm{VGluT}}$ neurons, is enhanced. Therefore, $\mathrm{VP}_{\mathrm{VGluT2}}$ neurons may be more strongly inhibited by the NAc after withdrawal from cocaine. This should be checked thoroughly in future studies.

\section{The "aversive connection" of $\mathrm{VP}_{\mathrm{VGluT2}}$ neurons}

An overall look at the data reveals that the $\mathrm{VP}_{\text {VGluT2 }}$ neurons are strategically connected to targets previously associated with aversion, and that cocaine CPP followed by abstinence affects these aversive connections, opposite to its effect on the connections to the other, rewarding targets (Fig. 6). First, $\mathrm{VP}_{\mathrm{VGluT2}}$ neurons show a strong link to the LHb, a region strongly implicated in aversion (Baker et al., 2016), and to each other (as discussed above). Moreover, after cocaine CPP and abstinence, only the connections with $\mathrm{LHb}$ and $\mathrm{VTA}_{\mathrm{GABA}}$ neurons, themselves central to aversion (Tan et al., 2012; van Zessen et al., 2012; Baker et al., 2016; Meye et al., 2016; Morales and Margolis, 2017), are strengthened, whereas all other connections are weakened or not changed (Figs. 5, 6). Specifically, note that although the input to $\mathrm{VTA}_{\mathrm{GABA}}$ is potentiated after abstinence (via a presynaptic mechanism; Fig. $5 \mathrm{H}, I)$, the input to the rewarding $\mathrm{VTA}_{\mathrm{DA}}$ neurons is weakened (via a postsynaptic mechanism; Fig. $5 E$ ). It is also interesting to note that although the $\mathrm{VP}_{\mathrm{VGluT2}} \rightarrow \mathrm{LHb}$ projection is strengthened both pre- and postsynaptically, the $\mathrm{VP}_{\mathrm{VGluT} 2} \rightarrow$ $\mathrm{VTA}_{\mathrm{GABA}}$ is strengthened only through a presynaptic mechanism. This indicates that the VP is responsible for the fine-tuning of its own input to the VTA, but the LHb can strengthen the aversive signal from $\mathrm{VP}_{\mathrm{VGluT2}}$ neurons independent of $\mathrm{VP}_{\mathrm{VGluT2}}$ presynaptic changes. In other words, although $\mathrm{VP}_{\mathrm{VGluT2}}$ neurons may be the exclusive tuners of their own input to $\mathrm{VTA}_{\mathrm{GABA}}$ neurons, their input to the LHb is also controlled by the postsynaptic $\mathrm{LHb}$ neurons that can strengthen the synapse by recruiting more AMPA receptors to the synapse.

An overview of the aversive network, with its center in the $\mathrm{LHb}$, places $\mathrm{VP}_{\mathrm{VGluT} 2}$ neurons in a strategic position, where they can manipulate the activity both in the LHb and in the VTA. A simplified view of the LHb asserts that it drives aversion by inhibiting dopamine release from VTA $\mathrm{DA}_{\mathrm{DA}}$ neurons (Ji and Shepard, 2007; Matsumoto and Hikosaka, 2007; Graziane et al., 2018). This can be driven either by their excitatory drive on local $\mathrm{VTA}_{\mathrm{GABA}}$ neurons that inhibit $\mathrm{VTA}_{\mathrm{DA}}$ neurons (Omelchenko et al., 2009; Beier et al., 2015) or by driving the rostromedial tegmental nucleus to inhibit $\mathrm{VTA}_{\mathrm{DA}}$ neurons (Lammel et al., 2012; Graziane et al., 2018). Therefore, any glutamatergic drive on $\mathrm{LHb}$ neurons is expected to be aversive. Indeed, this was described for the excitatory input to the $\mathrm{LHb}$ from the entopeduncular nucleus (Shabel et al., 2012; Meye et al., 2016) and the lateral hypothalamus (Lazaridis et al., 2019; Trusel et al., 2019), and VP $\mathrm{VGluT2}_{\text {Th }}$ input is no difference in this aspect-activation of $\mathrm{VP}_{\mathrm{VGluT} 2}$ input to the LHb is aversive (Faget et al., 2018). However, the role of $\mathrm{VP}_{\mathrm{VGluT2}}$ neurons in aversion may be more complex, as they also directly target $\mathrm{VTA}_{\mathrm{GABA}}$ and $\mathrm{VTA}_{\mathrm{DA}}$ neurons. Thus, $\mathrm{VP}_{\mathrm{VGluT2}}$ neurons may drive aversion (after withdrawal) not only by activating the LHb but also by increasing their excitatory input to $\mathrm{VTA}_{\mathrm{GABA}}$ neurons, decreasing their excitatory input to $\mathrm{VTA}_{\mathrm{DA}}$ neurons, and decreasing their excitatory input to $\mathrm{VP}_{\mathrm{GABA}}$ neurons, which themselves inhibit mostly $\mathrm{VTA}_{\mathrm{GABA}}$ (Hjelmstad et al., 2013; Leung and Balleine, 2015). Therefore, $\mathrm{VP}_{\mathrm{VGluT2}}$ neurons may be a promising target for future examination of mechanisms underlying aversive symptoms in various psychiatric disorders.

\section{References}

Ahrens AM, Ferguson LM, Robinson TE, Aldridge JW (2018) Dynamic encoding of incentive salience in the ventral pallidum: dependence on the form of the reward cue. eNeuro 5:ENEURO.0328-17.2018.

Baker PM, Jhou T, Li B, Matsumoto M, Mizumori SJ, Stephenson-Jones M, Vicentic A (2016) The lateral habenula circuitry: reward processing and cognitive control. J Neurosci 36:11482-11488.

Bar-Yehuda D, Korngreen A (2008) Space-clamp problems when voltage clamping neurons expressing voltage-gated conductances. J Neurophysiol 99:1127-1136.

Beier KT, Steinberg EE, DeLoach KE, Xie S, Miyamichi K, Schwarz L, Gao XJ, Kremer EJ, Malenka RC, Luo L (2015) Circuit architecture of VTA dopamine neurons revealed by systematic input-output mapping. Cell 162:622-634.

Bengtson CP, Osborne PB (2000) Electrophysiological properties of cholinergic and noncholinergic neurons in the ventral pallidal region of the nucleus basalis in rat brain slices. J Neurophysiol 83:2649-2660.

Berninger B, Schinder AF, Poo MM (1999) Synaptic reliability correlates with reduced susceptibility to synaptic potentiation by brain-derived neurotrophic factor. Learn Mem 6:232-242.

Breese GR, Chu K, Dayas CV, Funk D, Knapp DJ, Koob GF, Lê DA, O’Dell LE, Overstreet DH, Roberts AJ, Sinha R, Valdez GR, Weiss F (2005) Stress enhancement of craving during sobriety: a risk for relapse. Alcohol Clin Exp Res 29:185-195.

Chavkin C, Koob GF (2016) Dynorphin, dysphoria, and dependence: the stress of addiction. Neuropsychopharmacology 41:373-374.

Counotte DS, Schiefer C, Shaham Y, O'Donnell P (2014) Time-dependent decreases in nucleus accumbens AMPA/NMDA ratio and incubation of sucrose craving in adolescent and adult rats. Psychopharmacology 231: $1675-1684$.

Creed M, Ntamati NR, Chandra R, Lobo MK, Lüscher C (2016) Convergence of reinforcing and anhedonic cocaine effects in the ventral pallidum. Neuron 92:214-226.

Dobi A, Margolis EB, Wang HL, Harvey BK, Morales M (2010) Glutamatergic and nonglutamatergic neurons of the ventral tegmental area establish local synaptic contacts with dopaminergic and nondopaminergic neurons. J Neurosci 30:218-229.

Faber DS, Korn H (1991) Applicability of the coefficient of variation method for analyzing synaptic plasticity. Biophys J 60:1288-1294

Faget L, Zell V, Souter E, McPherson A, Ressler R, Gutierrez-Reed N, Yoo JH, Dulcis D, Hnasko TS (2018) Opponent control of behavioral reinforcement by inhibitory and excitatory projections from the ventral pallidum. Nat Commun 9:849.

Geisler S, Zahm DS (2005) Afferents of the ventral tegmental area in the rat-anatomical substratum for integrative functions. J Comp Neurol 490: $270-294$.

Geisler S, Derst C, Veh RW, Zahm DS (2007) Glutamatergic afferents of the ventral tegmental area in the rat. J Neurosci 27:5730-5743.

Gipson CD, Kupchik YM, Shen H, Reissner KJ, Thomas CA, Kalivas PW (2013) Relapse induced by cues predicting cocaine depends on rapid, transient synaptic potentiation. Neuron 77:867-872.

Gladding CM, Raymond LA (2011) Mechanisms underlying NMDA receptor synaptic/extrasynaptic distribution and function. Mol Cell Neurosci 48:308-320.

Graziane NM, Neumann PA, Dong Y (2018) A focus on reward prediction and the lateral habenula: functional alterations and the behavioral outcomes induced by drugs of abuse. Front Synaptic Neurosci 10:12.

Gritti I, Mainville L, Jones BE (1993) Codistribution of GABA- with acetylcholine-synthesizing neurons in the basal forebrain of the rat. J Comp Neurol 329:438-457.

Hardingham GE, Bading H (2010) Synaptic versus extrasynaptic NMDA receptor signalling: implications for neurodegenerative disorders. Nat Rev Neurosci 11:682-696.

Heinsbroek JA, Bobadilla AC, Neuhofer DN, Kalivas PW (2017a) Cell type specific regulation of cocaine seeking in the ventral pallidum. Society for Neuroscience. Available at http://www.abstractsonline.com/pp8/index. html\#!/4376/presentation/17229.

Heinsbroek JA, Neuhofer DN, Griffin WC 3rd, Siegel GS, Bobadilla AC, Kupchik YM, Kalivas PW (2017b) Loss of plasticity in the D2accumbens pallidal pathway promotes cocaine seeking. J Neurosci 37: 757-767.

Hjelmstad GO, Xia Y, Margolis EB, Fields HL (2013) Opioid modulation of 
ventral pallidal afferents to ventral tegmental area neurons. J Neurosci 33:6454-6459.

Hur EE, Zaborszky L (2005) Vglut2 afferents to the medial prefrontal and primary somatosensory cortices: a combined retrograde tracing in situ hybridization study [corrected]. J Comp Neurol 483:351-373.

Ji H, Shepard PD (2007) Lateral habenula stimulation inhibits rat midbrain dopamine neurons through a $\mathrm{GABA}(\mathrm{A})$ receptor-mediated mechanism. J Neurosci 27:6923-6930.

Kalivas PW, Volkow ND (2005) The neural basis of addiction: a pathology of motivation and choice. Am J Psychiatry 162:1403-1413.

Kauer JA, Malenka RC (2007) Synaptic plasticity and addiction. Nat Rev Neurosci 8:844-858.

Kourrich S, Rothwell PE, Klug JR, Thomas MJ (2007) Cocaine experience controls bidirectional synaptic plasticity in the nucleus accumbens. J Neurosci 27:7921-7928.

Kupchik YM, Kalivas PW (2013) The rostral subcommissural ventral pallidum is a mix of ventral pallidal neurons and neurons from adjacent areas: an electrophysiological study. Brain Struct Funct 218:1487-1500.

Kupchik YM, Scofield MD, Rice KC, Cheng K, Roques BP, Kalivas PW (2014) Cocaine dysregulates opioid gating of GABA neurotransmission in the ventral pallidum. J Neurosci 34:1057-1066.

Kupchik YM, Brown RM, Heinsbroek JA, Lobo MK, Schwartz DJ, Kalivas PW (2015) Coding the direct/indirect pathways by D1 and D2 receptors is not valid for accumbens projections. Nat Neurosci 18:1230-1232.

Lammel S, Lim BK, Ran C, Huang KW, Betley MJ, Tye KM, Deisseroth K, Malenka RC (2012) Input-specific control of reward and aversion in the ventral tegmental area. Nature 491:212-217.

Lazaridis I, Tzortzi O, Weglage M, Märtin A, Xuan Y, Parent M, Johansson Y, Fuzik J, Fürth D, Fenno LE, Ramakrishnan C, Silberberg G, Deisseroth K, Carlén M, Meletis K (2019) A hypothalamus-habenula circuit controls aversion. Mol Psychiatry 24:1351-1368.

Leung BK, Balleine BW (2015) Ventral pallidal projections to mediodorsal thalamus and ventral tegmental area play distinct roles in outcomespecific pavlovian-instrumental transfer. J Neurosci 35:4953-4964.

Lu L, Grimm JW, Hope BT, Shaham Y (2004) Incubation of cocaine craving after withdrawal: a review of preclinical data. Neuropharmacology 47 [Suppl 1]:214-226.

Mahn M, Prigge M, Ron S, Levy R, Yizhar O (2016) Biophysical constraints of optogenetic inhibition at presynaptic terminals. Nat Neurosci 19: $554-556$.

Matsumoto M, Hikosaka O (2007) Lateral habenula as a source of negative reward signals in dopamine neurons. Nature 447:1111-1115.

Meye FJ, Soiza-Reilly M, Smit T, Diana MA, Schwarz MK, Mameli M (2016) Shifted pallidal co-release of GABA and glutamate in habenula drives cocaine withdrawal and relapse. Nat Neurosci 19:1019-1024.

Morales M, Margolis EB (2017) Ventral tegmental area: cellular heterogeneity, connectivity and behaviour. Nat Rev Neurosci 18:73-85.

Naassila M, Pierrefiche O (2019) Glun2b subunit of the NMDA receptor: the keystone of the effects of alcohol during neurodevelopment. Neurochem Res 44:78-88.

Neumann PA, Wang Y, Yan Y, Wang Y, Ishikawa M, Cui R, Huang YH, Sesack SR, Schlüter OM, Dong Y (2016) Cocaine-induced synaptic alterations in thalamus to nucleus accumbens projection. Neuropsychopharmacology 41:2399-2410.

Omelchenko N, Bell R, Sesack SR (2009) Lateral habenula projections to dopamine and GABA neurons in the rat ventral tegmental area. Eur J Neurosci 30:1239-1250.

Paoletti P, Bellone C, Zhou Q (2013) NMDA receptor subunit diversity: impact on receptor properties, synaptic plasticity and disease. Nat Rev Neurosci 14:383-400.

Pascoli V, Hiver A, Van Zessen R, Loureiro M, Achargui R, Harada M, Flakowski J, Lüscher C (2018) Stochastic synaptic plasticity underlying compulsion in a model of addiction. Nature 564:366-371.

Paxinos G, Franklin KBJ (2001) The mouse brain in stereotaxic coordinates, Ed 2. San Diego: Academic.

Richard JM, Ambroggi F, Janak PH, Fields HL (2016) Ventral pallidum neurons encode incentive value and promote cue-elicited instrumental actions. Neuron 90:1165-1173.

Richard JM, Stout N, Acs D, Janak PH (2018) Ventral pallidal encoding of reward-seeking behavior depends on the underlying associative structure. Elife 7:e33107.

Root DH, Melendez RI, Zaborszky L, Napier TC (2015) The ventral pallidum: subregion-specific functional anatomy and roles in motivated behaviors. Prog Neurobiol 130:29-70.

Schinder AF, Berninger B, Poo M (2000) Postsynaptic target specificity of neurotrophin-induced presynaptic potentiation. Neuron 25:151-163.

Shabel SJ, Proulx CD, Trias A, Murphy RT, Malinow R (2012) Input to the lateral habenula from the basal ganglia is excitatory, aversive, and suppressed by serotonin. Neuron 74:475-481.

Smith KS, Berridge KC (2005) The ventral pallidum and hedonic reward: neurochemical maps of sucrose "liking" and food intake. J Neurosci 25:8637-8649.

Smith KS, Tindell AJ, Aldridge JW, Berridge KC (2009) Ventral pallidum roles in reward and motivation. Behav Brain Res 196:155-167.

Stephenson-Jones M, Bravo-Rivera CC, Fernandes-Henriques C, Li B (2017) Genetically distinct ventral pallidal neurons encode the motivation for reward approach and punishment avoidance. Society for Neuroscience. Available at http://www.abstractsonline.com/pp8/index.html\#!/4376/ presentation/7018.

Tachibana Y, Hikosaka O (2012) The primate ventral pallidum encodes expected reward value and regulates motor action. Neuron 76:826-837.

Tan KR, Yvon C, Turiault M, Mirzabekov JJ, Doehner J, Labouèbe G, Deisseroth K, Tye KM, Lüscher C (2012) GABA neurons of the VTA drive conditioned place aversion. Neuron 73:1173-1183.

Tindell AJ, Smith KS, Peciña S, Berridge KC, Aldridge JW (2006) Ventral pallidum firing codes hedonic reward: when a bad taste turns good. J Neurophysiol 96:2399-2409.

Tooley J, Marconi L, Alipio JB, Matikainen-Ankney B, Georgiou P, Kravitz AV, Creed MC (2018) Glutamatergic ventral pallidal neurons modulate activity of the habenula-tegmental circuitry and constrain reward seeking. Biol Psychiatry 83:1012-1023.

Trusel M, Nuno-Perez A, Lecca S, Harada H, Lalive AL, Congiu M, Takemoto K, Takahashi T, Ferraguti F, Mameli M (2019) Punishment-predictive cues guide avoidance through potentiation of hypothalamus-to-habenula synapses. Neuron 102:120-127.e4.

van Zessen R, Phillips JL, Budygin EA, Stuber GD (2012) Activation of VTA GABA neurons disrupts reward consumption. Neuron 73:1184-1194.

Williams SR, Mitchell SJ (2008) Direct measurement of somatic voltage clamp errors in central neurons. Nat Neurosci 11:790-798. 